\title{
1 Changes in social cohesion in a long-lived species under a perturbation
}

\section{2 regime}

3 Genovart, M. ${ }^{\mathrm{a}, \mathrm{b}}{ }^{*}$, Gimenez, O. ${ }^{\mathrm{c}}$, Bertolero, A. ${ }^{\mathrm{d}}$, Choquet, R. ${ }^{\mathrm{c}}$, Oro, D. ${ }^{\mathrm{a}, \mathrm{b}}$,

4 Pradel, R. ${ }^{\mathrm{c}}$

5

6

7

8

9

${ }^{a}$ CEAB (CSIC), Carrer Accés Cala Sant Francesc, 14, 17300 Blanes

${ }^{\mathrm{b}}$ IMEDEA (CSIC-UIB), Miquel Marquès 21, 07190 Esporles

c CEFE, CNRS, Univ Montpellier, Univ Paul Valéry Montpellier 3, EPHE, IRD, 34293, Montpellier, France

${ }^{\mathrm{d}}$ Associació Ornitològica Picampall de les Terres de l’Ebre, Amposta

*Corresponding author: m.genovart@csic.es

\section{Abstract}

1. Understanding the behaviour of a population under perturbations is crucial and can help to mitigate the effects of global change. Sociality can influence the dynamics of behavioural processes and plays an important role on populations' resilience. However little is known about the effects of perturbations on the social cohesion of group-living animals.

2. To explore the strength of social cohesion and its dynamics under perturbations, we studied an ecological system involving a colonial, long-lived species living in a site experiencing a shift to a perturbed regime. This regime, caused by the invasion of predators, led this colony to hold from $70 \%$ to only $3 \%$ of the total 
world population in only one decade. Because birds breed aggregated in discrete and annually changing patches within large colonies, we could disentangle whether annual aggregation was random or resulted from social bonding among individuals. Our goals were 1) to uncover if there was any long-term social bonding between individuals and 2) to examine whether the perturbation regime affected social cohesion.

3. We explored social cohesion by means of contingency tables and, within the Social Network Analysis framework, by modeling interdependencies among observations using additive and multiplicative effects (AME) and accounted for missing data. We analysed 25 years of monitoring with an individual capturerecapture database of more than 3,500 individuals.

4. We showed that social bonding occurs over years in this species. We additionally show that social bonding strongly decreased after the perturbation regime. We propose that sociality and individual behavioural heterogeneity have been playing a major role driving dispersal and thus population dynamics over the study period.

5. Perturbations may lead not only to changes in individuals' behaviours and fitness but also to a change in populations' social cohesion. The demographic consequences of the breaking down of social bonds are still not well understood, but they can be critical for population dynamics of social species. Further studies considering individual heterogeneity, sociality and different types of perturbations should be carried out to improve our understanding on the 
bioRxiv preprint doi: https://doi.org/10.1101/686451; this version posted June 28, 2019. The copyright holder for this preprint (which was

not certified by peer review) is the author/funder, who has granted bioRxiv a license to display the preprint in perpetuity. It is made available under aCC-BY-NC-ND 4.0 International license.

49 Keywords: Audouin's gull, colonial species, decision-making, non-linear response,

50 perturbations, resilience, social cohesion, social network analyses. 


\section{Introduction}

52 Ecosystems are subject to perturbations, both natural and human induced, affecting individuals, populations and communities. When they are strong or are maintained through time, these perturbations may cause a shift in individual or population states or phases and even lead to collapses and extinctions (Dai, Korolev, \& Gore, 2015; Dakos, Carpenter, van Nes, \& Scheffer, 2014). Understanding how individuals and populations will respond to these perturbations is critical both from a 'pure' ecological standpoint and also from an applied point of view to mitigate the effects of global change (Colchero et al., 2018; Coulson et al., 2017; Donohue et al., 2016). Population dynamics may be directly affected by these perturbations through a decrease in demographic parameters such as survival or fecundity, or by a change, immediate or delayed, on individual behaviour, such as an increase in dispersal (Fernandez-Chacon et al., 2013). We define population resilience as the maximal pulse perturbation a population can tolerate or absorb without going extinct (Dai et al., 2015; Holling, 1973). In social animals, social behavioural processes, such as information sharing and decisionmaking, add another dimension to understanding the resilience of populations facing perturbations. For instance, the amount of social information can be enhanced not only by positive density-dependence, but also by social cohesion (Barrett, Henzi, \& Lusseau, 2012; Centola, 2018; Kerth, Perony, \& Schweitzer, 2011). Social bonds favor the exchange of private information and consequently reduce uncertainty in resource acquisition (e.g. shelter against predators, food, mates) or in decision-making in the face of disturbances, such as dispersal to non-perturbed or less perturbed sites (FernandezChacon et al., 2013; Snijders, Blumstein, Stanley, \& Franks, 2017; Webber \& Vander Wal, 2018). Thus, the structure of a group affects social interaction, information transfer, and collective decisions (Sueur \& Mery, 2017). However, little is known about 
the effects of perturbations on the social cohesion of populations in empirical studies of social animals.

The analysis of social relationships in animal populations may include from simple and ephemeral contacts, to permanent and strong bonds between individuals (Firth \& Sheldon, 2015; Genton et al., 2015; Kerth et al., 2011; Leu, Farine, Wey, Sih, \& Bull, 2016). Coloniality is a life-history strategy where individuals show a clear social relationship among conspecifics, breeding in large and dense groups (Brown, 2016; Rolland, Danchin, \& de Fraipont, 1998). However, many colonial species are philopatric, thus this relationship may not necessarily reflect individual social bonds but a shared tendency to breed in the same birthplace. This tendency may result from the need to share information about resources, especially when they are patchy and more unpredictable, or it may result from the advantages of social defence against predators (Clode, 1993; Hoogland \& Sherman, 1976). A challenge lies in disentangling whether annual association between individuals is only due to philopatry, or also due to the existence of a social bonding within groups of individuals over time. If the latter is true, then this would suggest the evolution of social cohesion for exploiting the evolutionary advantages of social living (including social information sharing) for individual fitness prospects.

Social network theory, originated in sociology and widely used to study human relationships and social organization (Centola, 2018; Moreno, 1934; Scott, 1988) now provides both a conceptual framework and the analytical tools to explore social

97 cohesion and social processes in animal populations (Croft, James, \& Krause, 2008; Farine \& Whitehead, 2015; Ward \& Webster, 2016; Whitehead, 2014). Network theory

99 is now being simultaneously developed in a number of fields, including statistical

100 physics, sociology, molecular biology, and computer science. As a result the field is 
101 changing at a rapid pace. While not all developments can or should be applied toward

102 the study of animal societies (James, Croft, \& Krause, 2009), this rush of novel ideas

103 from outside disciplines is enriching behavioural ecology (Hasenjager \& Dugatkin,

104 2015).

105 To explore the existence of social cohesion and its dynamics under perturbations, we

106 studied an ecological system involving a colonial, social vertebrate (the Audouin's gull

107 Larus audouinii) living in a site experiencing a shift to a perturbed regime. Interestingly

108 from a social point of view, the species breeds aggregated in spatially-discrete patches

109 within large colonies. Each breeding season, some patches go extinct and some are

110 colonized, forcing individuals to breed in patches different from the ones they were born

111 in or they bred in the previous year. These colonization-extinction processes may allow

112 us to disentangle whether social aggregation among individuals is an annual random

113 association, or it rather results from social cohesion among individuals. An extensive

114 long-term monitoring program has been carried out since 1988 at the Ebro Delta,

115 comprising the main breeding site for the species, the Punta de la Banya (M. Genovart,

116 Oro, \& Tenan, 2018). Here, population dynamics has undergone different phases: an

117 initial growing phase after site colonization, an exponential growth phase, a stable phase

118 of dynamic equilibrium, and a final transition phase to population collapse (Almaraz \&

119 Oro, 2011; Figure 1). This collapse was due to the arrival of terrestrial predators, and

120 led this colony to hold from $70 \%$ to only $3 \%$ of the total world population in only a

121 decade (Figure 1; M. Genovart et al., 2018; Payo-Payo et al., 2018). The perturbation

122 regime caused changes in the spatial distribution of patches at the site, changes in age

123 structure, decrease in fecundity and an increase of dispersal to other sites (Payo-Payo et

124 al., 2017, 2018). 
125 Taking advantage of the long-term monitoring of this long-lived species, the knowledge

126 of its population dynamics, and the use of tools recently developed in the Social

127 Network Analysis (SNA) framework, we specifically addressed the following

128 questions: 1) is there any long-term social bonding between individuals breeding in the

129 same patch and 2) have perturbations, in this case a perturbation regime, affected social

130 cohesion? We finally discuss the role and consequences of social cohesion in population

131 dynamics and resilience in social species.

\section{Material and Methods}

\section{$134 \quad$ Study species and study area}

135 The Audouin's gull is a long-lived seabird with more than $80 \%$ of the global population

136 breeding in the western Mediterranean (http://www.iucnredlist.org/details/22694313/0;

137 M. Genovart et al., 2018). This species was critically endangered until the early 80's,

138 when it colonized a new site, the Punta de la Banya in the Ebro Delta (Figure 2). Here,

139 the large availability of both suitable breeding habitat and food resulted in a rapid and

140 exponential growth, ending with the site holding more than $70 \%$ of the total world

141 population in 2006 . The global population dynamics was mainly driven by this colony

142 and after the exponential growth, the species was downgraded to a conservation

143 category of "least concern" (IUCN 2015). However, the Punta de la Banya colony is

144 now collapsing and even if the species is colonizing new sites, the global population is

145 decreasing at a 5\% annual rate (M. Genovart, Oro, \& Tenan, 2018; Figure 1). In 1997,

146 first carnivores (mainly foxes, but also badgers, beech martens and least weasels)

147 arrived at Punta de la Banya, and since then the site has been perturbed to a greater or

148 lesser extent by carnivores. 
149 Annual censuses of breeding pairs at every patch within colonies at the Ebro Delta area

150 have been carried out since colonization in 1981 to 2017 (Figure 1 and 2; Figure S2). In

151 the Ebro Delta there are three colonies: Punta de la Banya, colonized in 1981 and

152 occupied throughout the study period, Sant Carles de la Ràpita harbour, occupied since

1532011 to 2015, and Sant Antoni, occupied from 2013 up to now (Figure 2, Figure S1).

154 Within colonies, individuals are distributed in patches or sub-colonies (Meritxell

155 Genovart, Jover, Ruiz, \& Oro, 2003, Figure 2). As patch location may change from one

156 year to another, we annually geolocalized, mapped and defined the breeding patches

157 (Figure 2, Figure S1).

$158 \quad$ Individual data

159 During 1988-2017 a total of 30,290 individuals were captured and ringed as chicks at

160 the Punta de la Banya (Meritxell Genovart, Pradel, \& Oro, 2012; Oro, Tavecchia, \&

161 Genovart, 2010). From 2002 to 2017 resightings were made using spotting scopes from

162 a distance all over the western Mediterranean with a total of 63,106 resights in the study

163 area and 5,593 different individuals resighted. Each year we recorded the breeding patch

164 for each individual. To make sure that individuals were breeding and that they did so in

165 a particular patch, we only selected those individuals seen during the breeding season in

166 a particular patch showing unequivocal breeding behaviour. Specifically, individuals

167 making alarm calls, incubating eggs or with chicks. After this selective filter our final

168 database included 3,548 individuals.

169 SNA framework

170 Our social network, defined as the observed pattern of breeding association, was

171 constructed taking individuals as the nodes of the network and each edge dyad (i.e. pair

172 of individuals) representing the fact that individuals breed in the same patch. We ended

173 with a global sociomatrix, i.e. the matrix representation of the dyadic relationships 
174 among individuals, of 3,548*3,548. Depending on the question addressed, edges

175 showed if two individuals bred in the same patch one year, or at least once in a certain

176 period (see below). The network was not directional. The strength of association

177 between dyads was calculated using the half-weight association index (HWI) more

178 suitable when not all individuals within each group have been identified (Cairns \&

179 Schwager, 1987; Ginsberg \& Young, 1992). In our case, the HWI measures the

180 proportion of time individuals have bred together, from 0 (never bred together) to 1

181 (never observed breeding apart). Based on previous results on population dynamics, and

182 on the population size of this species and colony (M. Genovart et al., 2018; Payo-Payo

183 et al., 2017), we divided our dataset in two main periods: a period defined as "stable

184 phase" from 2002 to 2011 , and a period of "transition phase to collapse", from 2012 to

1852017 (Figure 1).

186 For some of our analyses we used the recently developed AME function from the

187 AMEN package (Hoff, 2018; Minhas, Hoff, \& Ward, 2016) that can be applied to

188 binary, ordinal, and continuous network data. This new approach uses an iterative

189 Markov chain Monte Carlo (MCMC) algorithm that provides Bayesian inference of the

190 parameters in the social relations regression model (SRM; Warner, Kenny, \& Stoto,

191 1979) using additive and multiplicative effects and combining the linear regression

192 model with the covariance structure of the SRM (Minhas et al., 2016). The AME

193 method is also able to cope with missing and censored data; this is highly relevant when

194 analysing sociality on wild populations, as detection rate for individuals is almost

195 always imperfect, and properly controlling for missed observations is a very important

196 step in social network analysis (Gimenez et al., 2019; Hoppitt \& Farine, 2018). To our

197 knowledge, this is the first application of the AME approach in an ecological context.

198 To create and visualize our networks we used the packages Amen (Hoff, 2018), Asnipe 
199 (Farine, 2013), gdata (Warnes 2017) and igraph in R (Csardi, Gabor; Nepusz Tamas,

200 2006).

201 Are there social bonds that persist over time?

202 We investigated if individuals create social bonds that persist over time longer than one

203 breeding occasion by means of two approaches i) contingency tables and ii) the

204 inclusion of time dependent regression terms in the AME modelling framework

205 (Minhas et al., 2016) (see previous section). To answer this question, we analysed data

206 of the period of stability, from 2002 to 2011, dividing this period into two sub-periods

207 of five years (2002-2006 and 2007-2011). In the contingency table approach we tested if

208 the probability of breeding together at least once during the second sub-period was

209 independent of having bred together before at least once in the first period. We built a

$2103 \times 3$ table of frequencies, showing the frequencies of two individuals breeding or not

211 together at least once during the second sub-period depending on if they bred together

212 or not at least once during the first sub-period. We included a third column/line for

213 unknown relationships, i.e. with no information for one or the two of the individuals for

214 that period. We then tested for deviation of random frequencies by Chi Square test.

215 With the SNA approach we analysed the social bond between individuals using the

216 AME function provided in the Amen package in $\mathrm{R}$ and including data from the first

217 period (five previous years) as predictors of association during the second sub-period.

218 We considered that this time window was not too large to include important death

219 events, but large enough to account for the imperfect detection of individuals. To

220 achieve convergence, we increased the number of iterations to 100,000 from the default

221 value of 10,000 and lengthened the burn-in period to 500 .

222 Had perturbations affected social cohesion in this species? 
223 To assess if perturbations affected social structure in this species, we analysed as

224 previously, with both the contingency table approach and the SNA approach, the social

225 bonding during the period of "transition phase to collapse" (2012-2017). To do so, we

226 tested if the probability of breeding together in this phase (2012-2017) was independent

227 of having bred together during five previous years (2007-2011). We then compared

228 these results from those previously observed during the "stability phase".

$230 \quad$ Results

231 We analysed a total of 1,610,922 dyadic interactions during the first period (2002-2011)

232 and 368,142 during the second period (2012-2017) (Figure 3).

233 When assessing the social bonding with the contingency table approach, the assumption

234 that breeding aggregations in Audouin's gull were at random was rejected, and those

235 individuals that bred together during the sub-period 2002-2006 had a higher probability

236 of breeding together during the sub-period 2007-2011 $\left(\chi^{2}=64.685,1 \mathrm{df}, \mathrm{P}\right.$ value $<$

$2370.0001)$.

238 Accordingly, when assessing the social bond with dependent regression terms in the

239 AME function, we show that the probability of breeding together during the second sub-

240 period (2007-2011) depended on whether they have bred previously together in the first

241 sub-period (2002-2006), with a statistically significant coefficient of regression

242 parameter (Table 1; Figure 3).

243 When we analysed the social bonding during the transition to collapse phase, we

244 observed that the probability of breeding together during the period 2012-2017 did not

245 depend on if they have bred together the five previous years $\left(\chi^{2}=1.957\right.$, $\mathrm{p}$-value $=$

246 0.162) and we could not reject the hypothesis of a random association between

247 individuals. Also the SNA approach showed that breeding aggregations in Audouin's 
248 gull during the transition phase did not depend on if they have bred together the five

249 previous years (Table 1; Figure 3).

\section{Discussion}

252 By studying a particular ecological system of a colonial long-lived species that

253 experiences a perturbation regime, we showed that social bonding among individuals

254 persist over the years and that perturbations may decrease social cohesion in animal

255 populations.

256 The characteristic breeding behaviour of the study species that aggregates in patches

257 that change annually, allowed us to show that individuals do not annually breed

258 aggregated at random but rather there is some group stability, with individuals

259 establishing social bonds that persist over time. Group stability can emerge as a product

260 of network self-organization, but may provide the necessary conditions for the evolution

261 of other social processes (Cantor \& Farine, 2018; Cantor et al., n.d.). Our results would

262 support the idea that social aggregation during breeding would provide other advantages

263 than the mere defence against predators (Anderson \& Hodum, 1993; Oro, 1996), such

264 as social information sharing. Social information sharing is crucial for decision-making

265 in risky behaviours, such as dispersal, and previous studies showed that the perturbed

266 regime in this site caused dispersal to other sites, including colonization of new habitats

267 (Payo-Payo et al., 2017, 2018). Our results suggest that sociality has played a major role

268 driving dispersal and thus populations dynamics in this species, both during the

269 exponential growth after colonization and the collapse after the perturbation regime.

270 The importance of social information compared to private information is larger under

271 perturbations, even when the quality of social information does not increase compared

272 to a non-perturbed regime (Arganda, Pérez-Escudero, \& Polavieja, 2012; Pérez- 
273 Escudero \& Polavieja, 2017). Under stress conditions, sociality may operate through

274 feedback loops such as social copying for dispersal, causing non-linear population

275 dynamics and playing a critical role on the resilience of populations. We showed here

276 that after a perturbation, not only the number of individuals in the population may

277 decrease (by increased mortality or dispersal) but also its social cohesion, reducing the

278 amount of social information available for those individuals that remain. The

279 perturbation regime suffered by this population has likely triggered a social transition

280 (Pruitt et al., 2018) in collective behaviour from philopatric to dispersal and with the

281 fast diffusion of innovations such as the colonization of harbours, a habitat safe from

282 predators never occupied before (Payo-Payo et al., 2017). Previous studies have shown

283 that responses of populations to perturbations may also depend on individual

284 personalities in the population (Dall, Houston, \& McNamara, 2004; Doering, Scharf,

285 Moeller, \& Pruitt, 2018; Wolf, van Doorn, Leimar, \& Weissing, 2007). For example

286 individual personalities have recently been shown to influence dispersal (Clobert, Le

287 Galliard, Cote, Meylan, \& Massot, 2009; Cote, Clobert, Brodin, Fogarty, \& Sih, 2010;

288 Fogarty, Cote, \& Sih, 2011). Heterogeneities in personalities for dispersal decision-

289 making may have also played a role in this population, with most individuals dispersing

290 to other sites after a period of disturbance, while some individuals remaining

291 philopatric. This probably would have led to a change in the individual personalities

292 composition of the population. This change may have also further consequences, as

293 performance in social systems may improve with heterogeneity in individual

294 personalities in the social group (Fogarty et al., 2011; O'Shea-Wheller, Masuda,

295 Sendova-Franks, \& Franks, 2017).

296 This study opens new research questions about resilience of populations under

297 perturbations; if perturbations are able to affect social cohesion and heterogeneity in 
personalities in the population, would the perturbed populations be equally resilient to future perturbations? Additionally, in our study population, sociality seemed to operate not right after the first perturbation episode but after a period of maintained

301 perturbations (Payo-Payo et al., 2017); would the type of perturbation, either pulse or in

302 regime (Nimmo, Mac Nally, Cunningham, Haslem, \& Bennett, 2015) influence the

303 response of social groups?

304 We have shown here that perturbations may decrease social cohesion in animal

305 populations, but further studies should be carried out to improve our understanding on

306 the demographic consequences of the breaking down of social bonds under

307 perturbations for population dynamics and resilience on social species.

309 Acknowledgements

310 We would like to thank all the people who have helped with the fieldwork in the Ebro

311 delta over the years, particularly Albert Bertolero, Julia Piccardo, Toni Curcó and the

312 technical staff and volunteers at the Ebro Delta Natural Park. We would also like to

313 thank Peter Hoff, for solving an analytical problem that we encountered at the beginning

314 of the analyzes with the AMEN R package. We also thank the Regional Government of

315 Catalonia, for permits to access the study sites. Elisabeth Rochon corrected the English.

316 Funding came from the Spanish Ministry of Science (CGL2017-85210), Consell Insular

317 de Menorca and grant PICS INTERACT n07699 (2016, CSIC-CNRS). MG was

318 partially supported by the European Union (MINOUW Project, H2020-634495).

\section{Authors contributions}

321 MG conceived the idea; MG, OG, RP and RC designed methodology; MG, DO and AB

322 collected the data; MG analysed the data; MG led the writing of the manuscript. All

323 authors critically contributed to the drafts and gave final approval for publication. 


\section{Data accessibility}

Data is available via CSIC repository.

\section{References}

Almaraz, P., \& Oro, D. (2011). Size-mediated non-trophic interactions and stochastic predation drive assembly and dynamics in a seabird community. Ecology, 92(10), 1948-1958.

Anderson, D. J., \& Hodum, P. J. (1993). Predator Behavior Favors Clumped Nesting in an Oceanic Seabird. Ecology, 74(8), 2462-2464. doi: 10.2307/1939597

Arganda, S., Pérez-Escudero, A., \& Polavieja, G. G. de. (2012). A common rule for decision making in animal collectives across species. Proceedings of the National Academy of Sciences, 109(50), 20508-20513. doi: 10.1073/pnas.1210664109

Barrett, L., Henzi, S. P., \& Lusseau, D. (2012). Taking sociality seriously: the structure of multi-dimensional social networks as a source of information for individuals. 367(1599), 2108-2118. doi: 10.1098/rstb.2012.0113

346 Brown, C. R. (2016). The ecology and evolution of colony-size variation. Behavioral Ecology and Sociobiology, 70(10), 1613-1632. doi: 10.1007/s00265-016-2196-x

348 Cairns, S. J., \& Schwager, S. J. (1987). A comparison of association indices. Animal Behaviour, 35(5), 1454-1469. doi: 10.1016/S0003-3472(87)80018-0 
350 Cantor, M., \& Farine, D. R. (2018). Simple foraging rules in competitive environments can generate socially structured populations. Ecology and Evolution, 8(10), 4978-4991. doi: 10.1002/ece3.4061

Cantor, M., Maldonado-Chaparro, A., Beck, K., Carter, G., He, P., Hillemann, F., ... Farine, D. R. (n.d.). Animal social networks: revealing the causes and implications of social structure in ecology and evolution. doi:

Centola, D. (2018). How Behavior Spreads: the Science of Complex Contagions.

Clobert, J., Le Galliard, J.-F., Cote, J., Meylan, S., \& Massot, M. (2009). Informed dispersal, heterogeneity in animal dispersal syndromes and the dynamics of spatially structured populations. Ecology Letters, 12(3), 197-209. doi:

Clode, D. (1993). Colonially breeding seabirds: Predators or prey? Trends in Ecology \& Evolution, 8(9), 336-338. doi: 10.1016/0169-5347(93)90242-H

Colchero, F., Jones, O. R., Conde, D. A., Hodgson, D., Zajitschek, F., Schmidt, B. R., ... Gaillard, J. (2018). The diversity of population responses to environmental change. Ecology Letters. doi: 10.1111/ele.13195

Cote, J., Clobert, J., Brodin, T., Fogarty, S., \& Sih, A. (2010). Personality-dependent dispersal: characterization, ontogeny and consequences for spatially structured populations. Philosophical Transactions of the Royal Society B: Biological

372 Coulson, T., Kendall, B. E., Barthold, J., Plard, F., Schindler, S., Ozgul, A., \& Gaillard, J.-M. (2017). Data from: Modeling adaptive and nonadaptive responses of populations to environmental change [Data set]. doi: 10.5061/dryad.4c117 
375 Croft, D. P., James, R., \& Krause, J. (2008). Exploring Animal Social Networks. Retrieved from https://www.jstor.org/stable/j.ctt7sfqv

377 Csardi, G.; Nepusz T. (2006). The igraph software package for complex network research. InterJournal. Retrieved from http://igraph.org

Dai, L., Korolev, K. S., \& Gore, J. (2015). Relation between stability and resilience determines the performance of early warning signals under different environmental drivers. Proceedings of the National Academy of Sciences, 112(32), 10056-10061. doi: 10.1073/pnas.1418415112

Dakos, V., Carpenter, S. R., van Nes, E. H., \& Scheffer, M. (2014). Resilience indicators: prospects and limitations for early warnings of regime shifts. Philosophical Transactions of the Royal Society B: Biological Sciences,

Dall, S. R. X., Houston, A. I., \& McNamara, J. M. (2004). The behavioural ecology of personality: consistent individual differences from an adaptive perspective. Ecology Letters, 7(8), 734-739. doi: 10.1111/j.1461-0248.2004.00618.x

Doering, G. N., Scharf, I., Moeller, H. V., \& Pruitt, J. N. (2018). Social tipping points in animal societies in response to heat stress. Nature Ecology \& Evolution, 2(8), 1298-1305. doi: 10.1038/s41559-018-0592-5

Donohue, I., Hillebrand, H., Montoya, J. M., Petchey, O. L., Pimm, S. L., Fowler, M. S., ... Yang, Q. (2016). Navigating the complexity of ecological stability.

396 Farine, D. R. (2013). Animal social network inference and permutations for ecologists in R using asnipe. Methods in Ecology and Evolution, 4(12), 1187-1194. doi: 
399 Farine, D. R., \& Whitehead, H. (2015). Constructing, conducting and interpreting animal social network analysis. Journal of Animal Ecology, 84(5), 1144-1163.

401 doi: $10.1111 / 1365-2656.12418$

Fernandez-Chacon, A., Genovart, M., Pradel, R., Tavecchia, G., Bertolero, A., Piccardo, J., ... Oro, D. (2013). When to stay, when to disperse and where to go: survival and dispersal patterns in a spatially structured seabird population. Ecography, in press.

Firth, J. A., \& Sheldon, B. C. (2015). Experimental manipulation of avian social structure reveals segregation is carried over across contexts. Proceedings of the Royal Society B: Biological Sciences, 282(1802), 20142350-20142350. doi: $10.1098 /$ rspb.2014.2350

Fogarty, S., Cote, J., \& Sih, A. (2011). Social Personality Polymorphism and the Spread of Invasive Species: A Model. The American Naturalist, 177(3), 273-287. doi: $10.1086 / 658174$

Genovart, M., Oro, D., \& Tenan, S. (2018). Immature survival, fertility, and density dependence drive global population dynamics in a long-lived species. Ecology, 99(12), 2823-2832. doi: 10.1002/ecy.2515

Genovart, M., Jover, L., Ruiz, X., \& Oro, D. (2003). Offspring sex ratios in subcolonies of Audouin's gull, Larus audouinii, with differential breeding performance. Canadian Journal of Zoology, 81(5), 905-910. doi: 10.1139/z03-069

419 Genovart, M., Pradel, R., \& Oro, D. (2012). Exploiting uncertain ecological fieldwork data with multi-event capture-recapture modelling: an example with bird sex assignment. Journal of Animal Ecology, 81(5), 970-977. doi: 10.1111/j.13652656.2012.01991.x 
423 Genton, C., Pierre, A., Cristescu, R., Lévréro, F., Gatti, S., Pierre, J.-S., ... Le Gouar, P. (2015). How Ebola impacts social dynamics in gorillas: a multistate modelling approach. Journal of Animal Ecology, 84(1), 166-176. doi: 10.1111/13652656.12268

Gimenez, O., Mansilla, L., Klaich, M. J., Coscarella, M. A., Pedraza, S. N., \& Crespo, E. A. (2019). Inferring animal social networks with imperfect detection. Ecological Modelling, 401, 69-74. doi: 10.1016/j.ecolmodel.2019.04.001

Ginsberg, J. R., \& Young, T. P. (1992). Measuring association between individuals or groups in behavioural studies. Animal Behaviour, 44, 377-379. doi: 10.1016/0003-3472(92)90042-8

Hasenjager, M. J., \& Dugatkin, L. A. (2015). Chapter Three - Social Network Analysis in Behavioral Ecology. In M. Naguib, H. J. Brockmann, J. C. Mitani, L. W. Simmons, L. Barrett, S. Healy, \& P. J. B. Slater (Eds.), Advances in the Study of Behavior (Vol. 47, pp. 39-114). doi: 10.1016/bs.asb.2015.02.003

Hoff, P. D. (2018). Additive and multiplicative effects network models. ArXiv:1807.08038 [Stat]. Retrieved from http://arxiv.org/abs/1807.08038

Holling, C. S. (1973). Resilience and Stability of Ecological Systems. Annual Review of Ecology and Systematics, 4(1), 1-23. doi:

Hoogland, J. L., \& Sherman, P. W. (1976). Advantages and Disadvantages of Bank Swallow (Riparia riparia) Coloniality. Ecological Monographs, 46(1), 33-58. doi: $10.2307 / 1942393$ relationships: how to deal with missing observations of individuals or groups. Animal Behaviour, 136, 227-238. doi: 10.1016/j.anbehav.2017.08.029 
448 James, R., Croft, D. P., \& Krause, J. (2009). Potential banana skins in animal social network analysis. Behavioral Ecology and Sociobiology, 63(7), 989-997. doi: $10.1007 / \mathrm{s} 00265-009-0742-5$

Kerth, G., Perony, N., \& Schweitzer, F. (2011). Bats are able to maintain long-term social relationships despite the high fission-fusion dynamics of their groups. Proceedings of the Royal Society B: Biological Sciences, 278(1719), 27612767. doi: $10.1098 / \mathrm{rspb} .2010 .2718$

Leu, S. T., Farine, D. R., Wey, T. W., Sih, A., \& Bull, C. M. (2016). Environment modulates population social structure: experimental evidence from replicated

Minhas, S., Hoff, P. D., \& Ward, M. D. (2016). Inferential Approaches for Network Analyses: AMEN for Latent Factor Models. ArXiv:1611.00460 [Stat]. Retrieved from http://arxiv.org/abs/1611.00460

Moreno, J. L. (1934). Who shall survive?: A new approach to the problem of human interrelations. doi: 10.1037/10648-000

Nimmo, D. G., Mac Nally, R., Cunningham, S. C., Haslem, A., \& Bennett, A. F. (2015). Vive la résistance: reviving resistance for 21 st century conservation. Trends in Ecology \& Evolution, 30(9), 516-523. doi: 10.1016/j.tree.2015.07.008

Oro, D. (1996). Colonial Seabird Nesting in Dense and Small Sub-Colonies: An Advantage against Aerial Predation. The Condor, 98(4), 848-850. doi: $10.2307 / 1369868$

Oro, D., Tavecchia, G., \& Genovart, M. (2010). Comparing demographic parameters for philopatric and immigrant individuals in a long-lived bird adapted to unstable habitats. Oecologia, 165(4), 935-945. doi: 10.1007/s00442-010-1773-3 
473 O'Shea-Wheller, T. A., Masuda, N., Sendova-Franks, A. B., \& Franks, N. R. (2017).

474

475

476 Variability in individual assessment behaviour and its implications for collective decision-making. Proceedings of the Royal Society B: Biological Sciences, 284(1848), 20162237. doi: 10.1098/rspb.2016.2237

Payo-Payo, A., Genovart, M., Sanz-Aguilar, A., Greño, J. L., García-Tarrasón, M., Bertolero, A., ... Oro, D. (2017). Colonisation in social species: the importance of breeding experience for dispersal in overcoming information barriers. Scientific Reports, 7. doi: 10.1038/srep42866

Payo-Payo, A., Sanz-Aguilar, A., Genovart, M., Bertolero, A., Piccardo, J., Camps, D., ... Oro, D. (2018). Predator arrival elicits differential dispersal, change in age structure and reproductive performance in a prey population. Scientific Reports, 8(1), 1971. doi: 10.1038/s41598-018-20333-0

Pérez-Escudero, A., \& Polavieja, G. G. de. (2017). Adversity magnifies the importance of social information in decision-making. Journal of The Royal Society Interface, 14(136), 20170748. doi: 10.1098/rsif.2017.0748

Pruitt, J. N., Berdahl, A., Riehl, C., Pinter-Wollman, N., Moeller, H. V., Pringle, E. G., ... Hobson, E. A. (2018). Social tipping points in animal societies. Proc. R. Soc. B, 285(1887), 20181282. doi: 10.1098/rspb.2018.1282

Rolland, C., Danchin, E., \& de Fraipont, M. (1998). The evolution of coloniality in birds in relation to food, habitat, predation, and life-history traits: a comparative analysis. American Naturalist, 151, 514-529.

Scott, J. (1988). Social Network Analysis. Sociology, 22(1), 109-127. doi: $10.1177 / 0038038588022001007$ 
Snijders, L., Blumstein, D. T., Stanley, C. R., \& Franks, D. W. (2017). Animal Social Network Theory Can Help Wildlife Conservation. Trends in Ecology \& Evolution, 32(8), 567-577. doi: 10.1016/j.tree.2017.05.005

Sueur, C., \& Mery, F. (2017). Social Interaction in Animals: Linking Experimental Approach and Social Network Analysis. Frontiers Media SA.

Ward, A., \& Webster, M. (2016). Sociality: The Behaviour of Group-Living Animals. Retrieved from //www.springer.com/gb/book/9783319285832

Warner, R. M., Kenny, D. A., \& Stoto, M. (1979). A new round robin analysis of variance for social interaction data. Journal of Personality and Social Psychology, 37(10), 1742-1757. doi: 10.1037/0022-3514.37.10.1742

Webber, Q. M. R., \& Vander Wal, E. (2018). An evolutionary framework outlining the integration of individual social and spatial ecology. Journal of Animal Ecology, 87(1), 113-127. doi: 10.1111/1365-2656.12773 Social Analysis.

511 Wolf, M., van Doorn, G. S., Leimar, O., \& Weissing, F. J. (2007). Life-history tradeoffs favour the evolution of animal personalities. Nature, 447(7144), 581-584. doi: $10.1038 /$ nature05835 
515 Table 1. Results of the AME regression function to test if there were social bonds

516 between individuals while breeding during the stable period and during the transition

517 phase to collapse period. The alternative hypothesis is that individuals aggregate

518 annually at random for breeding. ".dyad”: coefficient of the dependent regression term

519 considering the previous dyadic relationship between individuals; "pmean": posterior

520 mean estimate; "psd": posterior standard deviation; "z-stat ": nominal z-score.

521

\begin{tabular}{lllllllll}
\hline & & \multicolumn{3}{c}{ Stable period } & \multicolumn{4}{c}{ Transition to collapse period } \\
& pmean & psd & z-stat & p-value & pmean & psd & z-stat & p-value \\
\cline { 2 - 9 } intercept & -1.467 & $0.087-$ & 16.808 & 0.000 & -0.231 & 0.018 & -12.629 & 0.000 \\
.dyad & 6.420 & 0.328 & 19.576 & 0.000 & -0.004 & 0.022 & -0.188 & 0.851
\end{tabular}


bioRxiv preprint doi: https://doi.org/10.1101/686451; this version posted June 28,2019 . The copyright holder for this preprint (which was

not certified by peer review) is the author/funder, who has granted bioRxiv a license to display the preprint in perpetuity. It is made available under aCC-BY-NC-ND 4.0 International license.

524 Figure 1. Number of breeding pairs in the Punta de la Banya colony from colonization

525 in 1981 to 2017 . The observed phases in the population dynamics (initial growth,

526 dynamic equilibrium and collapse) are separated by grey lines, which are identified by

527 chronological clustering analysis (Almaraz \& Oro, 2011). Red arrow indicates the

528 arrival of predators to the colony; a resistance phase started with this invasion and

529 ended with the onset of the transition phase to collapse. Numbers above some years

530 show the percentage of total world population held at Punta de la Banya.

531

532

533

534

535

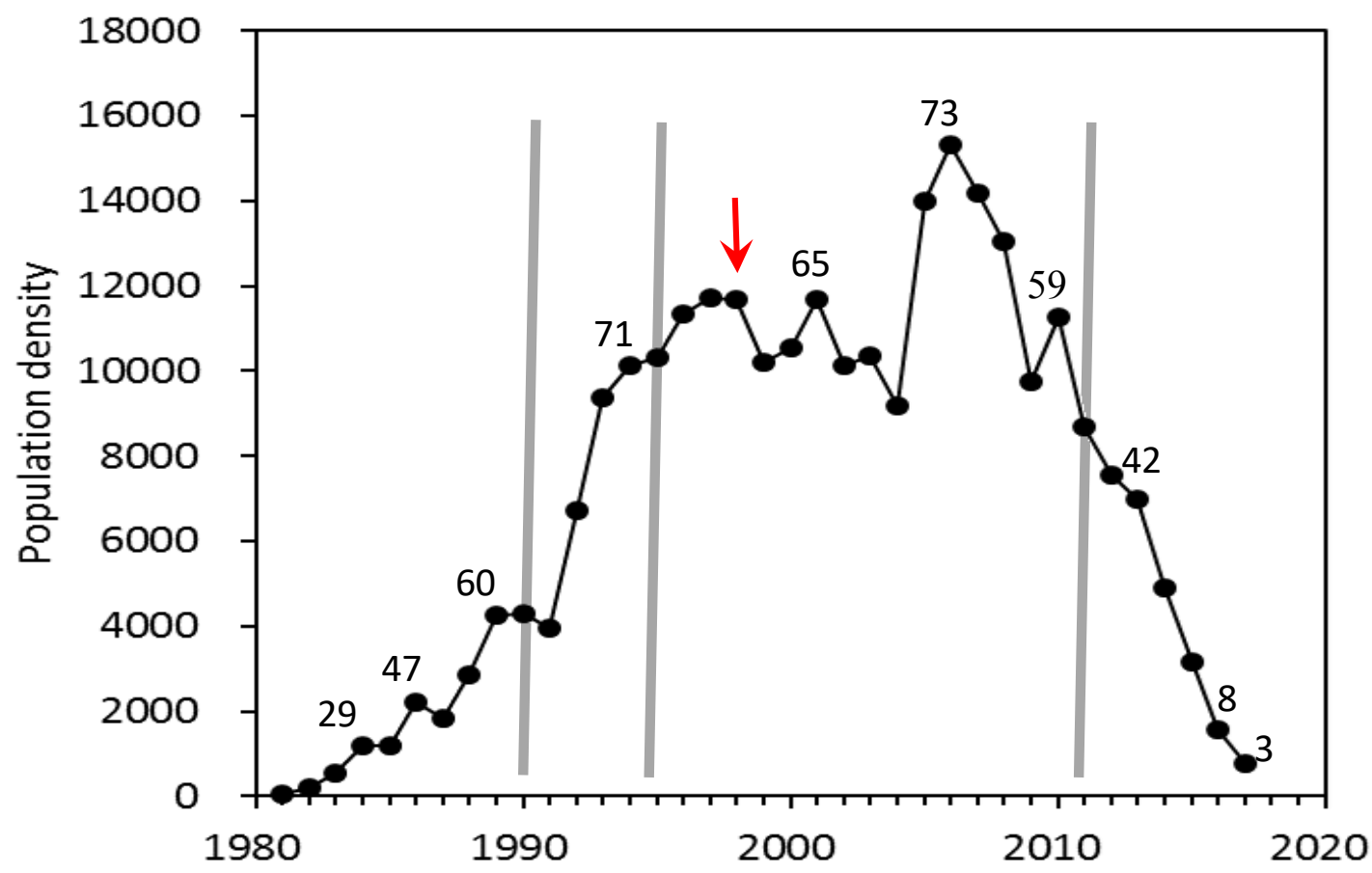


bioRxiv preprint doi: https://doi.org/10.1101/686451; this version posted June 28,2019 . The copyright holder for this preprint (which was

not certified by peer review) is the author/funder, who has granted bioRxiv a license to display the preprint in perpetuity. It is made available under aCC-BY-NC-ND 4.0 International license.

536 Figure 2. Map of the study area comprising the 3 main colonies and the distribution of

537 patches within colonies during the study period at a) Sant Antoni and b) Punta de la

538 Banya. Sant Carles de la Rápita colony is considered to have only one patch.

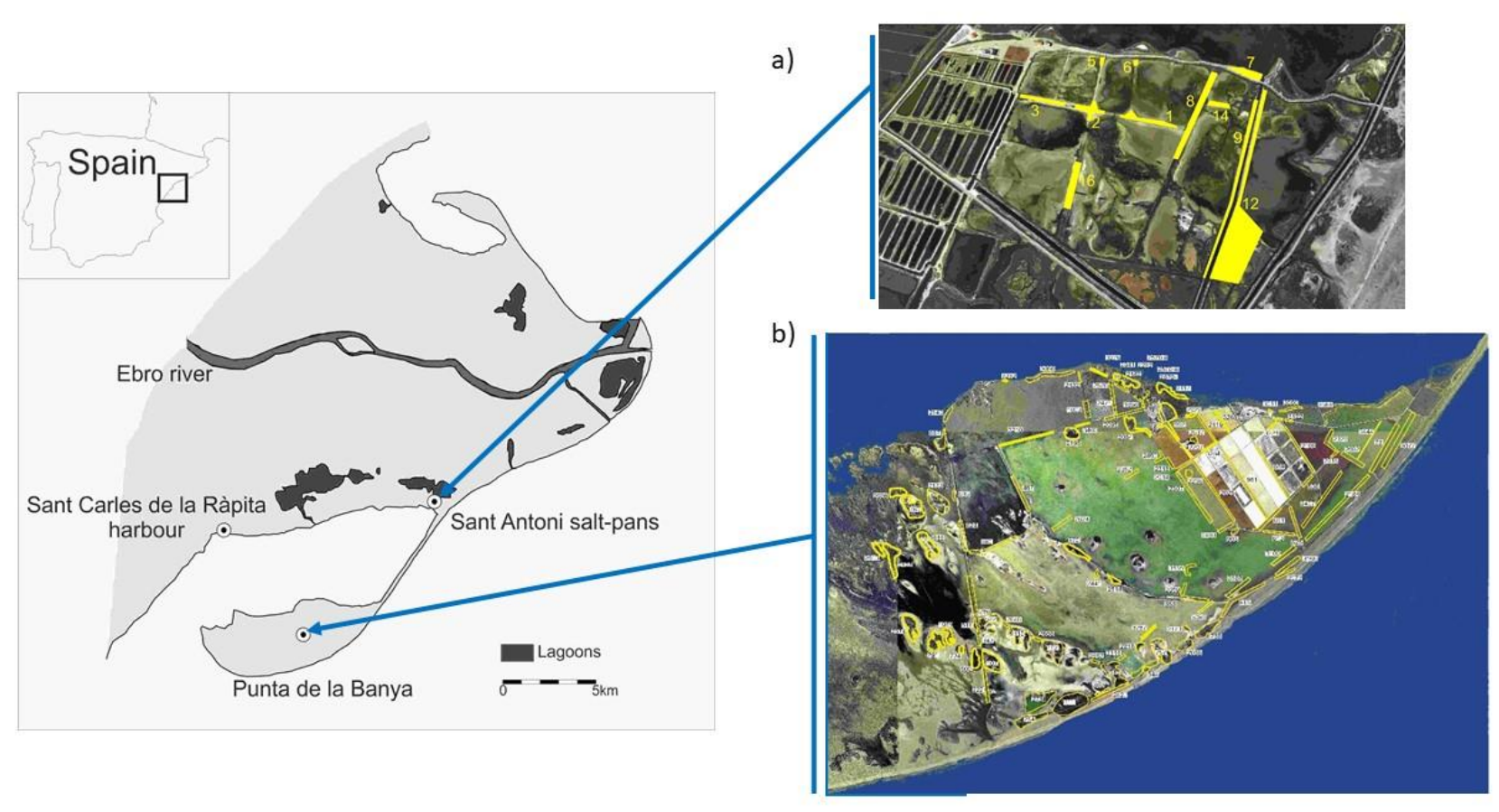


bioRxiv preprint doi: https://doi.org/10.1101/686451; this version posted June 28,2019 . The copyright holder for this preprint (which was

not certified by peer review) is the author/funder, who has granted bioRxiv a license to display the preprint in perpetuity. It is made available under aCC-BY-NC-ND 4.0 International license.

540 Figure 3. Graphical representation of social networks by the association between

541 individuals of Audouin's gulls in breeding patches comparing a) the stability phase

542 (2002-2011) and b) the transition phase to colony collapse (2012-2017) (see Figure 1).

543 Each node represents an individual and each edge links those individuals that have bred

544 together in the same patch.

545

546

a)

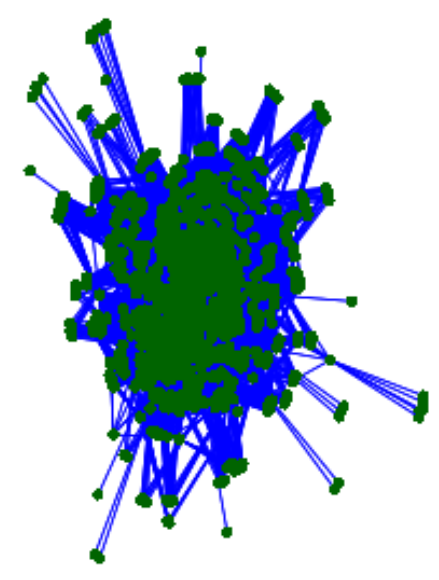

b)

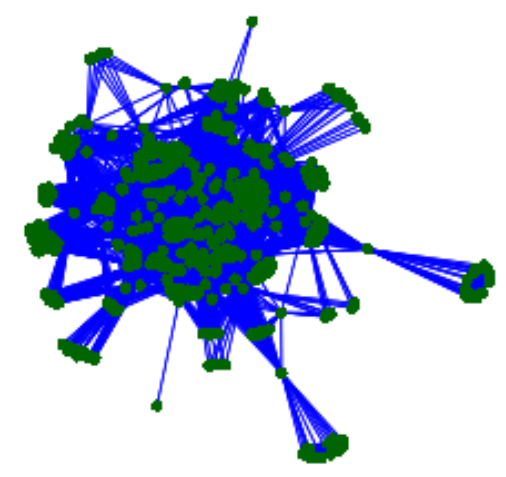

